\title{
Efficacy of Adding Atracurium to Percaruncular Block for High Myopes (A Randomized Controlled Trial)
}

\author{
MAHA M.A. MOSTAFA, M.D.*; NAZMY E. SEIF, M.D.*; MAHA M.I. YOUSSE, M.D.*; \\ MAHMOUD M. SOLIMAN, M.D.** and ASHRAF M. AMIN, M.D.* \\ The Departments of Anesthesia, Pain Management \& Surgical ICU* and Ophthalmology**, Faculty of Medicine, \\ Cairo University
}

\begin{abstract}
Background: In the current study, it was hypothesized that adding low dose atracurium to Local Anesthetic (LA) mixture would provide an early onset of akinesia and favorable surgical condition in percaruncular peribulbar anesthesia for high myopes undergoing phacoemulsification.

Methods: 91 ASA-PS I-III high myopes scheduled for phacoemulsification were enrolled in this randomized controlled trial. The enrolled patients were randomly allocated to one of two groups. Group C $(\mathrm{n}=46)$ received $2.5 \mathrm{ml}$ of lidocaine $2 \%, 2.5 \mathrm{ml}$ of bupivacaine $0.5 \%$ with hyaluronidase $15 \mathrm{IU} / \mathrm{ml}$ and $1 \mathrm{ml}$ normal saline, while patients in Group A $(\mathrm{n}=45)$ received the same mixture with $5 \mathrm{mg}$ atracurium. The onset of globe and eyelid akinesia and duration of akinesia were recorded. The need for supplementation, total LA volume and surgeons' satisfaction were recorded.
\end{abstract}

Results: Eighty-two patients were analyzed with 41 patient in each group. The onset of globe akinesia was earlier in Group A than Group C [4 (2-9), 4 (4-15) min. respectively, $p<0.001]$. Furthermore, fewer patients in Group A required supplementation compared to Group C, $27 \%$ versus $62 \%$ respectively, $p=0.002$. The onset of eyelid akinesia, duration of akinesia and the total volume of LA were comparative between the 2 groups.

Conclusion: Adding 5mg atracurium to LA solution reduced the time to onset of globe akinesia and the need for supplementation in the percaruncular block in myopic patients with no effect on duration of akinesia or quality of analgesia.

Key Words: Atracurium - Percaruncular - Medial canthalPeribulbar anesthesia - High myopes.

\section{Introduction}

THERE are several regional anesthetic techniques available for phacoemulsification procedures and the choice depends on patient, surgical and operator

Correspondence to: Dr. Maha M.A. Mostafa,

The Department of Anesthesia, Pain Management \& Surgical ICU, Cairo University, Egypt factors [1]. Patients with axial myopia (axial length more than $26 \mathrm{~mm}$ ) have thin sclera, limited space between globe and orbit and out-pouching of the sclera (staphyloma). Staphylomata are more frequently encountered inferior to the posterior pole (increasing the risk of perforation following an inferotemporal puncture in both peri-and retrobulbar blocks) [2-5] .

Single medial canthal peri-bulbar injection (percaruncular) may provide a safer and familiar alternative to inferotemporal peri- and retrobulbar techniques for phacoemulsification procedures in myopic patients. The space between the medial orbital wall and the globe is comparable to that of inferotemporal approach and devoid of blood vessels. Moreover, myopic staphylomata are infrequently located on the nasal side of the globe $[2,5-$ 8].

The effect of using non-depolarizing neuromuscular blockers as an adjuvant to the retrobulbar or peri-bulbar block, in developing early akinesia had been demonstrated in several studies [9-14]

The current study aimed to test the efficacy of adding low dose atracurium to lidocaine, bupivacaine and hyaluronidase mixture in providing an early onset of akinesia and favorable surgical condition in percaruncular peri-bulbar anesthesia for high myopes undergoing phacoemulsification.

\section{Material and Methods}

The protocol was registered in ClinicalTrials.gov under I.D. number: NCT03243500.

This was a single center parallel randomized controlled trial conducted in Ophthalmology Sur- 
gical Theater, Kasr Al-Ainy Hospital, Cairo, Egypt from May 2015 to May 2016.

After obtaining the Department of Anesthesia, Pain Management and Surgical ICU and Department of Ophthalmology Ethical Committee approbation, Cairo University Medical School approval (July, 2014) and informed consents from the patients, 91 American Society of Anesthesiologists' physical class (ASA-PS) I-III patients scheduled for phacoemulsification with high myopia (axial length $>26 \mathrm{~mm}$ ) were enrolled in the study.

Patients who were $<18$ or $>75$ years old, pregnant, ASA-PS $>$ III, their axial length was $<26 \mathrm{~mm}$ or had contraindication to regional anesthesia (absolute contraindications: Patient refusal to participate in the study, local anesthetic allergy and Infection/marked orbital inflammation or relative contraindications: Unable to lie flat for a sufficient length of time, confusion or psychiatric illness, communication difficulties, bleeding diathesis or taking anticoagulants, previous scleral buckling or space-occupying lesions within the orbit) were excluded from the study.

The enrolled patients were randomly allocated to one of two groups using a computer-generated number and concealed using sequentially numbered, sealed opaque envelopes. Group C $(n=46)$ received $2.5 \mathrm{ml}$ of lidocaine $2 \%$ (lidocaine hydrochloride $2 \%$ pharmacell $20 \mathrm{ml}$, manufactured by Sigmatec Pharmaceutical Industries, 6 October city, Egypt for Pharmacell Company, Egypt), 2.5ml of bupivacaine $0.5 \%$ (Sunnypivacaine $0.5 \% 20 \mathrm{ml}$ vial, Sunny Pharmaceutical, Badr City, Cairo, Egypt) with hyaluronidase $15 \mathrm{IU} / \mathrm{ml}$ (Omnidase 1500iu Injection, Sunways India Pvt Ltd, India. Diluted in 2 vial lidocaine $20 \mathrm{ml}$ resulting $37.5 \mathrm{IU} / \mathrm{ml}$ lidocaine and $93.7 / 2.5 \mathrm{ml}$ lidocaine or $15.6 \mathrm{IU} / \mathrm{ml}$ of the $6 \mathrm{ml}$ solution) and $1 \mathrm{ml}$ normal saline to make total volume of $6 \mathrm{ml}$, while patients in Group A $(\mathrm{n}=45)$ received $2.5 \mathrm{ml}$ of lidocaine $2 \%, 2.5 \mathrm{ml}$ of bupivacaine $0.5 \%$ with hyaluronidase $15 \mathrm{IU} / \mathrm{ml}$ and $5 \mathrm{mg}$ atracurium (Atracurium Hameln $10 \mathrm{mg} / \mathrm{ml}$ manufactured by Sunny Pharmaceutical, Badr City, Cairo, Egypt under license of Hameln Pharmaceuticals-Germany) in $1 \mathrm{ml}$ normal saline to make a total volume of $6 \mathrm{ml}$ from which the patient received $5-6 \mathrm{ml}$. Neither the administrator of the block nor the surgeon knew which drug mixture was given.

Preoperatively, the axial length of the enrolled patients was measured by ultrasound biometry and the presence of staphyloma was identified by Bscan.
In the preparation room, the Intravenous (IV) cannula was placed. Anxious patients were given midazolam intravenously (titrated to response according to patient's age and associated medical condition).

In the operating room, standard monitoring of pulse oximetry, Electrocardiography (ECG) and noninvasive arterial blood pressure were commenced. The $\mathrm{O}_{2}$ was administered at $2 \mathrm{ml} /$ minutes by the nasal $\mathrm{O}_{2}$ cannula.

Benoxinate $0.4 \%$ eye drops (BENOX® $0.4 \%$ $10 \mathrm{ml}$ Manufactured by Egyptian Int. Pharmaceutical Industries Co. (E.I.P.I.CO.)-Egypt) were instilled in the eye to be operated upon three times separated by a one-minute interval.

While in a supine position, the patient was asked to look directly ahead focusing on a fixed point on the ceiling so that the eyes were in the neutral position. A medial canthus injection was given using a $25 \mathrm{G}, 25 \mathrm{~mm}$ needle under complete aseptic condition. The needle insertion point was just medial to the caruncle. While the needle was perpendicular to the face, it was introduced parallel to the medial orbital wall to $15-20 \mathrm{~mm}$ depth [5]

After negative aspiration, the already chosen local anesthetic mixture was injected slowly. If the tension was felt to rise in the globe during injection (the globe was palpated with one finger and the lids tension was tested frequently) the injection would be stopped. After injection, external compression with Honan balloon inflated to $20-30 \mathrm{~mm}$ $\mathrm{Hg}$ was applied for 10 minutes and was removed every 2 minutes to test akinesia and anesthesia [5]

The data were recorded by the administrator of the block who was blinded to which drug mixture was given.

Ocular Movement Score (OMS) was assessed every 2 minutes by asking the patient to move his/ her eye in four directions; up, down, medially and laterally and the movement in each direction is given a score from 0 to 2 as follows: Movement more than $2 \mathrm{~mm}$ was given a score of $2,1-2 \mathrm{~mm}$ movement was given a score of 1 and no movement was given a score of 0 . A total score of 2 or less was considered adequate akinesia for surgery. The beginning of motor blockade (OMS < 6) and onset time of globe akinesia were recorded. Moreover, the OMS was assessed at the end of the surgery and then every 30 minutes post-operative till regaining full ocular movement to determine the duration akinesia [8] 
Eyelid movement score was assessed by asking the patient to open his/her eye widely followed by squeezing them maximally. A full movement was given a score of 2, the flickering was given a score of 1 and no movement was given a score of 0 . The time to score of $\leq 1$ was recorded [8]

If, after 10 minutes, the block was inadequate, a $3-4 \mathrm{ml}$ supplementation of lidocaine $2 \%$ by the same technique was given. If the block was still inadequate, it was considered a failure and excluded from the study. When the block was considered a failure the patient received either supplemental inferotemporal injection (if ultrasound excluded presence of posterior staphyloma), topical anesthesia, intravascular fentanyl 50mcg or general anesthesia according to the patient's condition. After adequate analgesia (loss of sensation to touch by a small cotton wool) and akinesia (OMS $\leq 2)$, the surgeon was allowed to start the surgery.

The need for supplementation and the total volume of the local anesthetic mixture were recorded. The pain was assessed by using a 3 point scoring system: (no pain $=0$, discomfort=1, pain=2) throughout the operation. If the score was $\geq 1$, we started by reassurance. If psychological reassurance failed, $50 \mathrm{mcg}$ fentanyl IV was given. Surgeons' satisfaction was assessed at the end of the surgical procedure by using a three-point scale: $0=$ not satisfied, $1=$ moderately satisfied, $2=$ satisfied.

\section{Statistical analysis:}

Statistical analysis was carried out using SPlus Statistical Software (SPSS) for Windows (Version 20.0, SPSS Inc. Chicago, Illinois). All variables were tested for normality using Kolmogorov-Smirnov test; if the test was significant, non-normality was accepted. Otherwise, doublechecking using graphs, skewness and kurtosis were required to confirm normality.

Continuous variables were described as mean \pm standard deviation when normality of distribution assumptions was satisfied. If not, it was presented as median [IQR]. Categorical variables were presented as numbers and percentages. Wilcoxon Matched-Pair Signed-Rank was used to compare paired nonparametric data. Two-tailed unpaired student $t$-test was used to compare quantitative variables, and Fisher's exact test was used to compare qualitative variables. A $p$-value of $<0.05$ was accounted to be significant.

Based on a two-sided alpha of $0.05,95 \%$ power, and a clinically relevant difference in time of onset of akinesia at least 3 minutes, a minimum of 74 patients was needed for the study (MedCalc $\AA$ version 12.7.1.0-64-bit).

\section{Results}

Ninety One patients scheduled for phacoemulsification in Kasr Al-Ainy Hospital were enrolled in the current study and randomly allocated to two groups [Group A $(n=45)$ and Group C $(n=46)$ ] from May 2015 to May 2016. Fig. (1) illustrates the enrollment, intervention allocation, follow-up, and data analysis. The nine excluded patients achieved adequate surgical condition after receiving an inferotemporal injection of $2 \mathrm{ml}$ lidocaine except for one patient (in Group C) who received superior nasal supplementation.

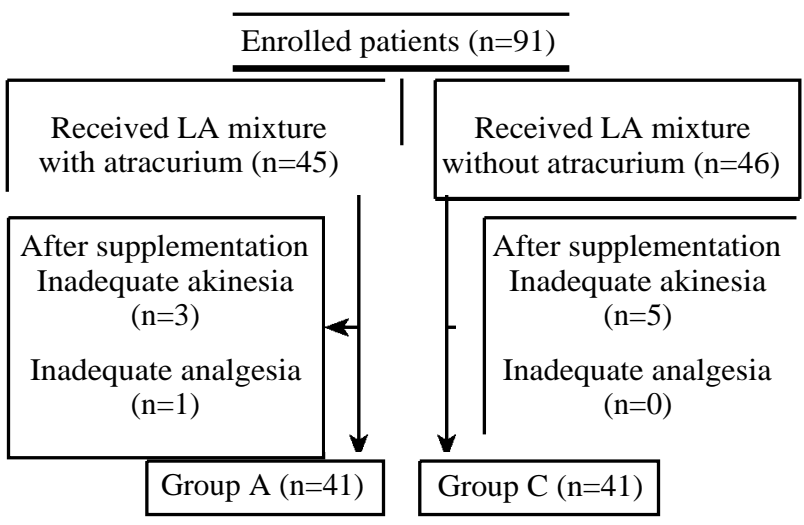

Fig. (1): Flow diagram of enrollment, intervention allocation, follow-up, and data analysis $\$$.

$\$+$ LA: Local Anesthesia.

The baseline demographic and clinical characteristics for the included 82 patients (41 for each group) are shown in Table (1).

Table (1): Demographic and clinical characteristics $\$$.

\begin{tabular}{llll}
\hline & $\begin{array}{c}\text { Group A } \\
(\mathrm{n}=41)\end{array}$ & $\begin{array}{c}\text { Group C } \\
(\mathrm{n}=41)\end{array}$ & $\begin{array}{c}p \text { - } \\
\text { value }\end{array}$ \\
\hline Age (years) & $49.2 \pm 8.21$ & $52.3 \pm 9.32$ & 0.493 \\
$\begin{array}{l}\text { Gender n (\%): } \\
\quad \text { Female }\end{array}$ & $22(54)$ & $22(54)$ & 1 \\
$\quad$ Male & $19(46)$ & $19(46)$ & \\
Axial length (mm) & $29[27.7-31]$ & $29[27-30]$ & 0.677 \\
Need for sedation n (\%) & $11(26.8)$ & $12(29.3)$ & 0.806 \\
Duration of the surgery (min.) & $45[35-60]$ & $50[40-60]$ & 0.601 \\
Posterior staphyloma n (\%) & $3(7.3)$ & $4(9.7)$ & 0.765 \\
ASA-PS n (\%): & & & \\
$\quad$ I & $19(46)$ & $17(41)$ & 0.656 \\
$\quad$ II & $20(49)$ & $18(44)$ & 0.658 \\
III & $2(5)$ & $6(15)$ & 0.264 \\
\hline
\end{tabular}

$\ddagger \ddagger$ : Numerical data were presented as mean \pm SD when normality of distribution assumptions was satisfied. If not, it was presented as median [IQR], categorical data were presented as frequency (\%), $p<0.05$ considered statistically significant.

ASA-PS: American Society of Anesthesiologists-Physical Status. 
Table (2) presents block criteria in each group. The onset of motor blockade and full akinesia were earlier in Group A compared to Group C. Furthermore, fewer patients in the Group A required supplementation compared to Group C. On the other hand, the onset of eyelid akinesia, the total volume of LA and the duration of akinesia were comparable between the two groups.

Table (2): Block criteria $\$ \neq$.

\begin{tabular}{|c|c|c|c|}
\hline & $\begin{array}{c}\text { Group A } \\
(\mathrm{n}=41)\end{array}$ & $\begin{array}{c}\text { Group C } \\
(n=41)\end{array}$ & $\begin{array}{c}p- \\
\text { value }\end{array}$ \\
\hline \multicolumn{4}{|l|}{ Onset time of: } \\
\hline OMS $\leq 6$ (min.) & $2[2-3]$ & $4 \quad[2-4]$ & $<0.001$ \\
\hline $\mathrm{OMS} \leq 2$ (min.) & $4[2-9]$ & $12[4-15]$ & $<0.001$ \\
\hline Eyelid akinesia (min.) & $4[2-4]$ & 4 [2-6] & 0.319 \\
\hline Total volume of LA (ml) & $6[5-8.5]$ & $8[5.5-9]$ & 0.061 \\
\hline Duration of akinesia (min) & $190[180-240]$ & $180[180-210]$ & 0.621 \\
\hline $\begin{array}{l}\text { - The incidence of } \\
\text { supplementation } \mathrm{n}(\%)\end{array}$ & $11(27)$ & $25(62)$ & 0.002 \\
\hline $\begin{array}{l}+\neq: \text { Numerical data were } \mathrm{p} \\
\text { were presented as freq } \\
\text { significant. }\end{array}$ & $\begin{array}{l}\text { sented as medi } \\
\text { ncy }(\%), p<0 \text {. }\end{array}$ & $\begin{array}{l}{[\mathrm{IQR}], \text { categor }} \\
\text { considered st }\end{array}$ & $\begin{array}{l}\text { istically data } \\
\text { isticall }\end{array}$ \\
\hline
\end{tabular}

In Group A, 5 (12\%) patients experienced pain compared to $6(14 \%)$ patients in Group C with no statistically significant difference. The experienced pain occurred toward the end of the surgery during Intraocular Lens (IOL) insertion except for one case in Group C, the pain occurred during irrigation and aspiration. Furthermore, the pain was mild that required only reassurance except for one patient in Group A and 2 in Group C who required 50mcg fentanyl intravenously.

Surgeons' satisfaction at the end of the surgery was comparable between the two groups. The current study surgeons found the operative conditions to be satisfactory (90\% in Group A and $83 \%$ in Group C) with 4 surgeons (10\%) in Group A and 7 surgeons (17\%) in Group C were less satisfied.

\section{Discussion}

The current study demonstrated the effect of adding low dose atracurium to lidocaine, bupivacaine and hyaluronidase mixture on providing an early onset of globe akinesia and favorable surgical condition in percaruncular peribulbar (PB) anesthesia for high myopes undergoing phacoemulsification.

In the current study, it was observed that onset of the motor blockade (OMS $\leq 6)$ and full akinesia $(\mathrm{OMS} \leq 2)$ was earlier in Group A than in Group C [4 (2-9), 4 (4-15) min. respectively].
The current study results were consistent with those reported by Küçü Kyavuz et al., [10] who have demonstrated that the addition of atracurium $5 \mathrm{mg}$ to a mixture of lidocaine $2 \%$ and bupivacaine $0.5 \%$ with volume of $8.5 \mathrm{ml}$ injected in inferotemporal quadrant and lateral to the supratrochlear notch, improve orbital akinesia and hasten block (onset time of akinesia was $10 \pm 3$ minutes in the control and $7 \pm 2$ minutes in the atracurium group, $p<0.05)$.

Furthermore, Eghbal et al., [14] noticed that adding $5 \mathrm{mg}$ atracurium to $2 \mathrm{~mL}$ of $2 \%$ lidocaine in retrobulbar anesthesia significantly decreased the onset time of akinesia $(4.7 \pm 1.1$ minutes in the atracurium group and $6.9 \pm 0.96$ minutes in the control group).

Rocuronium is another non-depolarizing neuromuscular blockers that had been studied in the peribulbar anesthesia [11,13]. Abdellatif et al., [11] reported that the addition of rocuronium $(5 \mathrm{mg})$ to a local anesthetic mixture of lidocaine $2 \%$ and bupivacaine $0.5 \%$ ( $4.25 \mathrm{ml}$ inferotemporal quadrant and $4.25 \mathrm{ml}$ percaruncular) significantly improved the time to adequate akinesia compared to control group $(6.9 \pm 4.1$ and $9.8 \pm 2.9$ minutes respectively, $p=0.01$ ). Aissaoui et al., [13] added rocuronium $0.06 \mathrm{mg} / \mathrm{kg}$ to the bupivacaine lidocaine mixture without hyaluronidase in a single inferotemporal injection. The authors found that rocuronium improved akinesia scores at 2, 5 and $10 \mathrm{~min}$ after the injection.

On the otherhand, Godarzi et al., [12] compared the effect of adding $0.5 \mathrm{ml}$ Atracurium $(5 \mathrm{mg}$ ) and $0.5 \mathrm{ml}$ cis-Atracurium $(1 \mathrm{mg}$ ) to bupivacaine $0.5 \%$, Lidocaine $2 \%$ and Hyaluronidase 90IU with the volume of $8.5 \mathrm{ml}$ in inferotemporal PB anesthesia. The study found that after 10 minutes, the percentage of akinesia was comparative among the 3 groups (92.6\% in the Atracurium group; $85.2 \%$ in the cis-Atracurium and the control group).

As regards to the need for supplementation, significantly fewer patients in the Group A required supplementation (due to the failure of the first injection to achieve adequate surgical condition after 10 minutes) compared to Group C, 27\% and $62 \%$ respectively. Aissaoui et al., [13] also demonstrated that Supplementary injections were lower in rocuronium group (13\%) than in control group $(40 \%)$.

On the otherhand, the need for supplementation was not reduced as reported in Küçü kyavuz et al., 10 (none in atracurium group and 2 cases in the control), and Abdellatif et al., [11] (20\% in rocuro- 
nium group and $30 \%$ in control group) while no supplementation was given in Eghbal et al. [14]

The reported higher rate of supplementations in the current study compared to the previously mentioned studies could be due to the use of techniques other than a single percaruncular injection in those studies $[\mathbf{1 0 - 1 3 , 1 5 ]}$. Furthermore in Küçü kyavuz et al., [10], supplementation was given after waiting 20 minutes (10 minutes in the current study). A larger initial volume of LA was used in Abdellatif et al., [11] and Aissaoui et al., [13]

Regarding the duration of akinesia in the current study, it was comparative between the 2 groups which was consistent with Küçü kyavuz et al., [10] results. On the other hand, adding atracurium to retrobulbar prolonged the duration of akinesia as reported by Eghbal et al., [14] . Other mentioned studies did not report the duration of akinesia $[11,12]$

In contrary to early onset of globe akinesia in Group A in the current study, it was observed that the onset of eyelid akinesia was not significantly earlier in Group A. This might be due to early spread of LA mixture to the eyelid through the percaruncular block which provides good orbicularis akinesia $[\mathbf{1 6 , 1 7 ]}$. Our results were comparable with Abdellatif et al., [11]. On the other hand, Küçü kyavuz et al., [10] observed that adding atracurium significantly hasten the onset of eyelid akinesia in inferotemporal PB. Also, Aissaoui et al., [13] noticed the earlier onset of eyelid akinesia in rocuronium when given in inferotemporal PB. Eghbal et al., [14] and Godarzi et al., [12] did not record the onset time of the eyelid akinesia.

Adding atracurium to LA solution in percaruncular block did not significantly lowered the total injected volume which was consistent with the observations of the previously mentioned studies [10-14]

The exact mechanism through which the local administration of a nondepolarizing muscle relaxant improves ocular akinesia is not known but is believed to be due to local effects at the muscle's motor end-plate $[\mathbf{1 0 , 1 1 , 1 4 ]}$.

In conclusion, adding $5 \mathrm{mg}$ atracurium significantly reduced the time of onset of globe akinesia and reduced the need for the second injection when added to LA solution in the percaruncular block in myopic patients. Furthermore, it did not affect the quality of analgesia or the duration of the akinesia with low risk of drug-related complications.

\section{References}

1- KUMAR C.M., et al.: Local anaesthesia for ophthalmic surgery-new guidelines from the Royal College of Anaesthetists and the Royal College of Ophthalmologists. Eye, 26: 897-8, 2012.

2- VOHRA S.B. and GOOD P.A.: Altered globe dimensions of axial myopia as risk factors for penetrating ocular injury during peribulbar anaesthesia. Br. J. Anaesth., 85: 242-5, 2000 .

3- EDGE R. and NAVON S.: Scleral perforation during retrobulbar and peribulbar anesthesia: Risk factors and outcome in 50000 consecutive injections. J. Cataract Refract. Surg., 25: 1237-44, 1999.

4- KUMAR C.: Orbital regional anesthesia: Complications and their prevention. Indian J. Ophthalmol.; 54: 77, 2006.

5- RIPART J., NOUVELLON E. and CHAUMERON A.: Regional anesthesia for eye surgery. Reg. Anesth. Pain Med., 30: 72-82, 2005.

6- ALLMAN K.G., McFADYEN J.G., ARMSTRONG J., STURROCK G.D. and WILSON I.H.: Comparison of articaine and bupivacaine/lidocaine for single medial canthus peribulbar anaesthesia. Br. J. Anaesth., 87: $584-$ 7,2001 .

7- DERUDDRE S. and BENHAMOU D.: Medial canthus single-injection peribulbar anesthesia: A prospective randomized comparison with classic double-injection peribulbar anesthesia. Reg. Anesth. Pain Med., 30: 2559, 2005.

8- SAMIR A. and GABAL A.: Percaruncular single injection peribulbar anaesthesia in patients with axial myopia for phacoemulsification. Saudi J. Ophthalmol. Off. J. Saudi Ophthalmol. Soc., 26: 87-90, 2012.

9- ALLAN T.W.B.: Systemic spread of vecuronium following use in peribulbar regional anaesthesia. Anaesthesia, 56: 1018-9, 2008.

10- Z.K., et al.: Effects of atracurium added to local anesthetics on akinesia in peribulbar block. Reg. Anesth. Pain Med., 27: 487-90, 2002.

11- ABDELLATIF A.A., EL-SHAHAWY M.A., AHMED A.I., ALMARAKBI W.A. and ALHASHEMI J.A.: Effects of local low-dose rocuronium on the quality of peribulbar anesthesia for cataract surgery. Saudi J. Anaesth., 5: 3604, 2011.

12- GODARZI M., et al.: Comparing the effect of using atracourium and cis-atracourium as adjuvant agents to the local anesthetic substance on peribulbar-induced akinesia. Acta Med. Iran., 49: 509-12, 2011.

13- AISSAOUI Y., BELYAMANI L. and DRISSI KAMILI N.: Effect of the addition of rocuronium to local anesthetics for peribulbar block. Acta Anaesthesiol. Belg., 61: 51-4, 2010 .

14- EGHBAL M.H., TABEI H., TAREGH S.A. and RAZEGHINEJAD M.R.: The effect of addition of low 
dose atracurium to local anesthetic in retrobulbar block for cataract surgery. Middle East J. Anesthesiol., 20: 5358,2010 .

15- GHALI A.M. and EL-BTARNY A.M.: The effect on outcome of peribulbar anaesthesia in conjunction with general anesthesia for vitreoretinal surgery. Anaesthesia, 65: 249-53, 2010.
16- JAICHANDRAN V.V.V.: Ophthalmic regional anaesthesia: A review and update. Indian J. Anaesth., 57: 7-13, 2013.

17- RIORDAN-EVA P.: In Vaughan \& Asbury's General Ophthalmology (eds. Riordan-Eva, P. \& Cunningham, E. T.) 15 (McGraw-Hill, 2011).

18- HUNTER J.M.: Histamine release and neuromuscular blocking drugs. Anaesthesia, 48: 561-3, 1993.

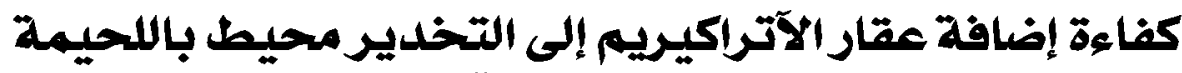 فى العين عند مرضى قصر الآير النظر}

المرضى الذين يعانون من قصر النظر المحوىى (طول محصىى آكثر من حبملم) هو معرضون الثقب العين بدون قصد آثناء حقن العين

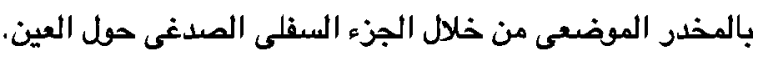

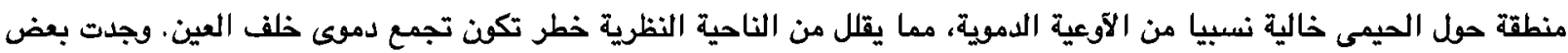

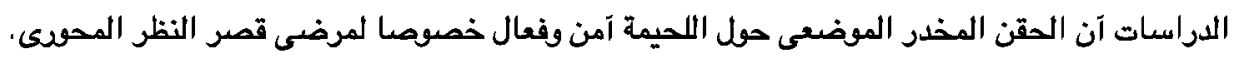

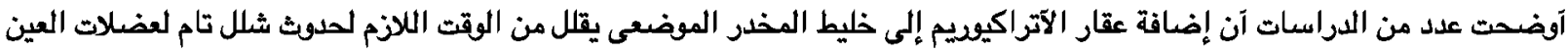

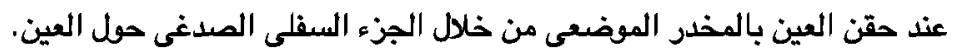

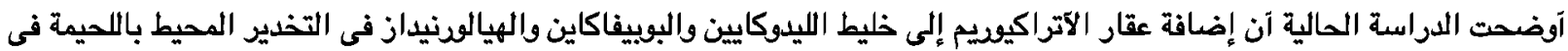

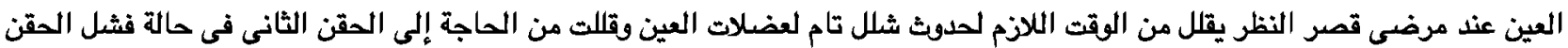
الآول من تحقيق شلل تام.

ولقد آوضحت الدراسة آيضا آن إضافة عقار الآتراكيويم إلى خليط المخدر الموضعى لم تؤثر على بداية فقدان الشعود بالآلم ولا مدة المّا

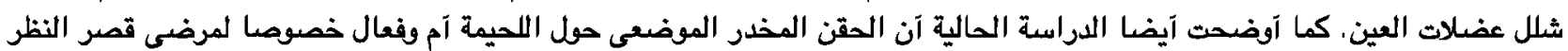

